\title{
Design of a Low-Voltage Distribution Transformer Based on Inductive Filtering
}

\author{
Delu LI*, Xianming DENG, Changyi LI, Xiao ZHANG, En FANG
}

\begin{abstract}
Adopting the connection group structure of Dd0yn11, this paper designs a novel low-voltage (LV) distribution transformer (DT) based on inductive filtering (IF), and verifies the proposed transformer through a comprehensive innovation experiment. Firstly, the functional relationship between valve-side harmonic current and grid-side current was derived according to the winding model, and the filtering features were obtained to compute the impedance between the valve- and grid-side windings. Next, the design calculation was carried out by the engineering magnetic circuit (EMC) method. After that, a three-dimensional (3D) model was established for the proposed transformer on ANSYS Maxwell. The simulation results show that the proposed transformer meets the design requirements on the relevant parameters, and eliminates the harmonic pollution in the grid. Finally, the proposed transformer was proved correct and effective through experiments, and found to stimulate students' interest in learning and innovation.
\end{abstract}

Keywords: ANSYS maxwell; distribution transformer (DT); finite-element simulation; harmonic governance; inductive filtering (IF)

\section{INTRODUCTION}

"Electric Machinery Fundamentals", a core course of electrical engineering and automation, focuses on the structure and working principle of direct current (DC) motors, transformers, asynchronous motors, and synchronous motors. One of the key objectives of this course is to enable students to put theories into practice: the students should be taught to design workable schemes for transformer and motor testing, to carry out experiments safely, and to collect and analyze the experimental data comprehensively.

To facilitate course teaching, a two-dimensional (2D) training mode gradually takes shape, which comprises a basic experiment and a comprehensive innovation experiment. The basic experiment aims to demonstrate the most fundamental experimental methods and operation skills, while the comprehensive innovation experiment intends to cultivate the ability to solve practical problems with the theoretical knowledge of electrical engineering, and to enhance the students' ability of scientific research. During the basic experiment, the electrical parameters of the transformer are measured under no-load state and shortcircuit state. During the comprehensive innovation experiment, the students are encouraged to renovate the structural design of transformers. In this study, an inductive filtering (IF) distribution transformer (DT) is designed, and tested through a comprehensive innovation experiment.

The proliferation of power electronic technology, coupled with the growing presence of nonlinear load, has brought harmonic pollution to the grid [1-3]. The transformer core is saturated to varied degrees by the highorder harmonic component in the grid. The ensuing problems, such as mechanical vibration, noise pollution, and core overheating, greatly reduce the service life of transformers [4-7]. Starting from the cross-winding equilibrium of magnetic potentials, the IF technology shields and filters the load-side harmonic current, and ensures the green operation of the grid.

Currently, IF is being widely applied in various highvoltage (HV) scenarios, including but not limited to trunk line electrification [8-13]. IF technology was first used to solve the quality problem of HVDC transmission and industrial DC power supply [14-16]. According to the actual situation of HVDC transmission and industrial DC power supply, the main connection modes of IF transformer are extended triangle and Ydd [17, 18].

The IF technology has the following advantages: Under the same voltage, the grid-side terminal employs the star connection, and controls the phase voltage at a low level, thereby reducing the cost of insulation materials [19, $20]$. On the valve side, the triangular connection is adopted to shield the 3rd harmonic and suppress the influence of zero sequence current [21]. In the LV distribution network, in order to obtain two voltages on the load side, the transformer winding generally adopts Dy wiring, which is mainly because the star connected on the load side has stronger capacity than the unbalanced load connected in triangle, and the three-phase unbalanced load needs to be grounded, which can meet the needs of urban power distribution $[22,23]$.

To popularize the application of IF technology in LV distribution network, this study improves 3-winding DT into a novel IF LV DT. Specifically, a side of the LV winding was changed into a filter winding, and a fully tuned branch was connected to eliminate the grid harmonics generated by 6-pulse rectification. To reduce cost and control loss, the proposed transformer uses the connection group structure of Dd0yn11. The filter boasts a high-quality factor, a few windings, and a small resistance. Finally, the proposed transformer was verified through simulation and experiment. The results show that the impedance of each winding met the design requirements, and the harmonic pollution was successfully eliminated.

The paper is organized as follows: Section II introduces the wiring scheme of the IF DT in LV distribution systems. Based on the strict analysis using the mathematical model of the proposed IF system, the working principle of harmonic attenuation is revealed. Section III presents the detailed winding design of the IF DT. Section IV selects ANSYS Maxwell to develop the electromagnetic model of the proposed DT and simulate the proposed filtering system on a benchmark LV distribution network. Section V verified the proposed IF method through experiment and concluding remarks are presented in Section VI.

\section{WIRING SCHEME AND MATHEMATICAL MODEL}

The proposed transformer adopts the connection group structure of Dd0yn11 to filter out the harmonic generated by 6-pulse rectification. As shown in Fig. 1, triangular 
connection is applied to the grid side and the filter side, while star connection to the valve side.

Fig. 2 gives the circuit topologies of distribution networks considering IF and traditional filters.

As is shown in Fig. 1a, for the traditional DT, filters are usually installed at the grid's side of the DT.

Fig. 1b presents the topology of the proposed IF system with Ddy connection DT. Unlike the traditional filter system the grid-side windings use the D connection, while the load-side windings use the $\mathrm{Y}$ connection. When the LV distribution network is connected with unbalanced loads, the load-side windings can also use the Yn connection.

The proposed filtering system has the following features:

(1) The winding adopts zero impedance design to balance the harmonic current at the load side and winding side, and the harmonic current can hardly flow into the power grid side. Therefore, the adverse effect of harmonic current on transformer is greatly reduced.

(2) In the IF system, the fully tuned filter branch does not need to be biased like the filter branch of traditional filter system. The parameters of the fully tuned filter branch can be calibrated according to the required tuning frequency.

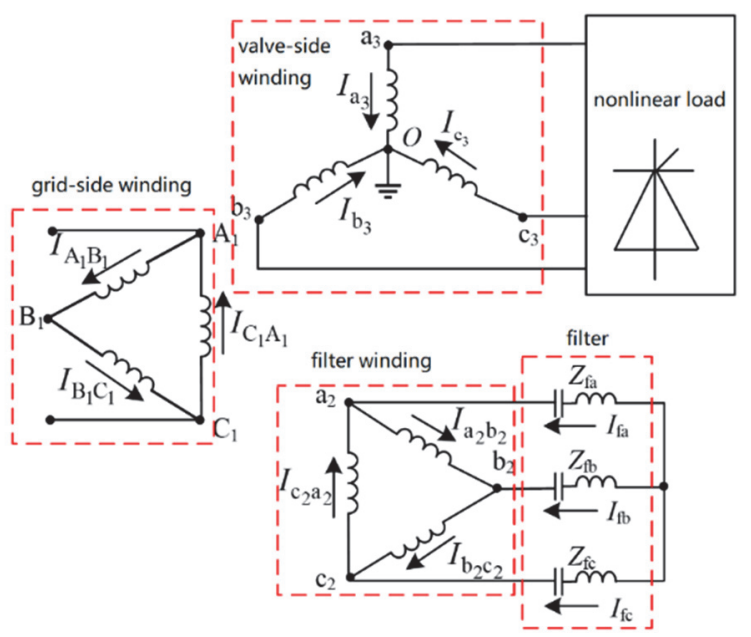

Figure 1 Wiring scheme

(3) When the system impedance is low, the performance of the traditional filtering system is easily affected by the system parameters. In IF system, the fully tuned filter branch is connected in parallel with the filterside winding of the DT, so IF system has the ability of anti resonance.

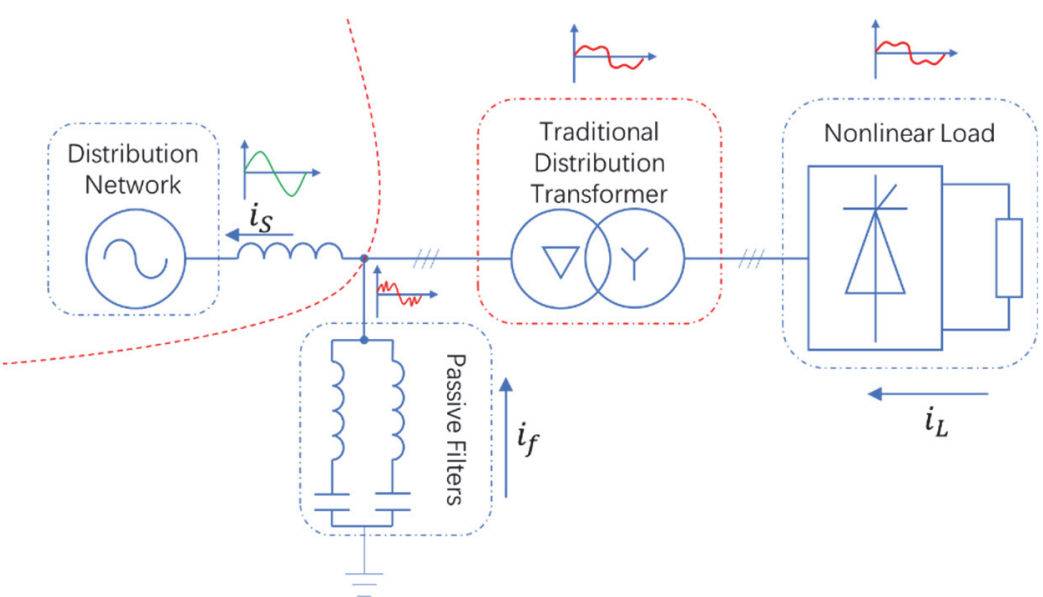

(a) Topologies of distribution networks considering traditional filters

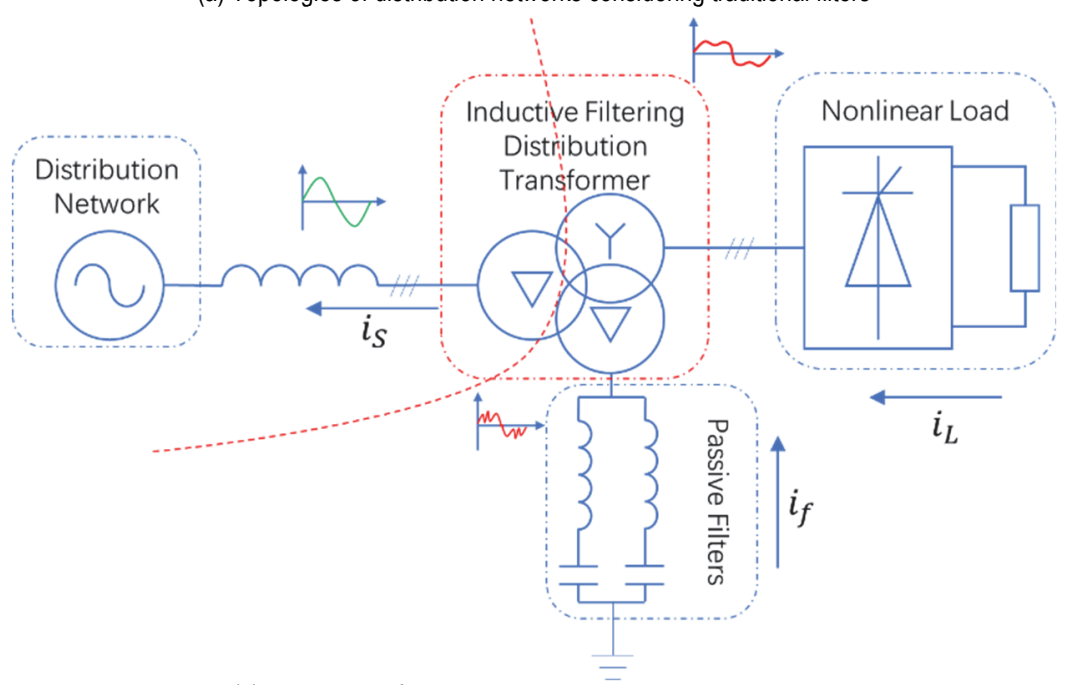

(b) Topologies of distribution networks considering the HIAF

Figure 2 Topologies of distribution networks considering IF and traditional filters

The proposed transformer consists of three windings. Among them, the filter-side winding is connected to a fully tuned branch. The impedances of the filter are denoted as
$Z_{\mathrm{fa}}, Z_{\mathrm{fb}}$ and $Z_{\mathrm{fc}}$. The filter boasts a high-quality factor, because it is immune to system impedance. Besides, the filter-side winding has a negligible loss of active power, 
owing to its few turns and low resistance.

Without considering the loss or current under no-load state and the excitation current, the power supply could be viewed as symmetric. That is, the power frequency curve exhibits as a perfect sine wave, and there is no difference in the parameters of the three windings. Because of the symmetry, a mathematical model was established for one phase only.

Drawing on the theories of transformers with multiple windings, the valve-side voltage, filter-side voltage, and grid-side voltage have the following relationship:

$$
\left\{\begin{array}{l}
\frac{W_{3}}{W_{1}} \dot{U}_{\mathrm{A}_{1} \mathrm{~B}_{1}}-\dot{U}_{\mathrm{a} 3 \mathrm{o}}=\frac{W_{1}}{W_{3}} \dot{I}_{\mathrm{A}_{1} \mathrm{~B}_{1}} Z_{31}+\frac{W_{2}}{W_{3}} \dot{I}_{\mathrm{a}_{2} \mathrm{~b}_{2}} Z_{3} \\
\frac{W_{3}}{W_{2}} \dot{U}_{\mathrm{a}_{2} \mathrm{~b}_{2}}-\dot{U}_{\mathrm{a} 3 \mathrm{o}}=\frac{W_{2}}{W_{3}} \dot{I}_{\mathrm{a}_{2} \mathrm{~b}_{2}} Z_{32}+\frac{W_{1}}{W_{3}} \dot{I}_{\mathrm{A}_{1} \mathrm{~B}_{1}} Z_{3}
\end{array}\right.
$$

where, $W_{1}, W_{2}$ and $W_{3}$ are the number of turns of grid-, filter-, and valve-side windings, respectively; $\dot{U}_{\mathrm{A}_{1} \mathrm{~B}_{1}}, \dot{U}_{\mathrm{a}_{2} \mathrm{~b}_{2}}$ and $\dot{U}_{\mathrm{a} 30}$ are valve-, filter-, and grid-side voltages, respectively; $Z_{3}$ is valve-side equivalent leakage impedance; $Z_{31}$ and $Z_{32}$ are the short-circuit impedances between valve- and grid-side windings, and between valveand filter-side windings; and $Z_{\mathrm{f}}=Z_{\mathrm{fa}}=Z_{\mathrm{fb}}=Z_{\mathrm{fc}}$ is the impedance of the filter.

Without considering the excitation current, the following can be derived from the equilibrium principle of magnetic potentials:

$$
W_{1} \dot{I}_{\mathrm{A}_{1} \mathrm{~B}_{1}}+W_{2} \dot{I}_{\mathrm{A}_{2} \mathrm{~B}_{2}}+W_{3} \dot{I}_{\mathrm{a}_{3}}=0
$$

Then, the current and voltage on the filter side can be respectively described by:

$$
\begin{aligned}
& \dot{I}_{\mathrm{fa}}=\dot{I}_{\mathrm{a}_{2} \mathrm{~b}_{2}}-\dot{I}_{\mathrm{c}_{2} \mathrm{a}_{2}}=\sqrt{3} \mathrm{e}^{-j 30^{\circ}} \dot{I}_{\mathrm{a}_{2} \mathrm{~b}_{2}} \\
& \dot{U}_{\mathrm{a}_{2} \mathrm{~b}_{2}}=Z_{\mathrm{f}}\left(\dot{I}_{\mathrm{fb}}-\dot{I}_{\mathrm{fc}}\right)=\sqrt{3} \mathrm{e}^{-j 150^{\circ}} Z_{\mathrm{f}} \dot{I}_{\mathrm{fa}}
\end{aligned}
$$

Hence, the filter-side current $\dot{I}_{\mathrm{a}_{2} \mathrm{~b}_{2}}$ has the following correlation with the grid-side current $\dot{I}_{\mathrm{A}_{1} \mathrm{~B}_{1}}$ :

$$
\dot{I}_{\mathrm{a}_{2} \mathrm{~b}_{2}}=\frac{\frac{W_{3}}{W_{1}} \dot{U}_{\mathrm{A}_{1} \mathrm{~B}_{1}}-\left(\frac{W_{1}}{W_{3}} Z_{31}-\frac{W_{1}}{W_{3}} Z_{3}\right) \dot{I}_{\mathrm{A}_{1} \mathrm{~B}_{1}}}{\left(\frac{W_{2}}{W_{3}} Z_{3}-\frac{W_{2}}{W_{3}} Z_{32}-\frac{3 W_{3}}{W_{2}} Z_{\mathrm{f}}\right)}
$$

Substituting the three winding impedance formulas $Z_{3}=\frac{1}{2}\left(Z_{31}+Z_{32}-Z_{12}^{(3)}\right)$ and $Z_{2}=\frac{1}{2}\left(Z_{21}+Z_{23}-Z_{31}^{(2)}\right)$ into Eq. (5) and combining Eq. (2), the grid-side current $\dot{I}_{\mathrm{A}_{1} \mathrm{~B}_{1}}$ has the following correlation with the valve-side current $\dot{I}_{\mathrm{a} 3}$ :

$$
\begin{gathered}
\dot{I}_{\mathrm{A}_{1} \mathrm{~B}_{1}}=\frac{\dot{U}_{\mathrm{A}_{1} \mathrm{~B}_{1}}}{\left(\frac{W_{1}}{W_{2}}\right)^{2}\left(Z_{2}+3 Z_{\mathrm{f}}\right)+Z_{1}}- \\
-\frac{W_{1} W_{3}\left(Z_{2}+3 Z_{\mathrm{f}}\right)}{\left(W_{1}\right)^{2}\left(Z_{2}+3 Z_{\mathrm{f}}\right)+W_{2}^{2} Z_{1}} \dot{I}_{\mathrm{a} 3}
\end{gathered}
$$

Without considering grid-side impedance, the gridside voltage $\dot{U}_{\mathrm{A}_{1} \mathrm{~B}_{1}}^{(n)}$ is zero for the $n$-th harmonic. Substituting $\dot{U}_{\mathrm{A}_{1} \mathrm{~B}_{1}}^{(n)}=0$ into Eq. (6):

$$
\dot{I}_{\mathrm{A}_{1} \mathrm{~B}_{1}}^{(n)}=-\frac{W_{1} W_{3}\left(Z_{2}^{(n)}+3 Z_{\mathrm{f}}^{(n)}\right)}{W_{1}^{2}\left(Z_{2}^{(n)}+3 Z_{\mathrm{f}}^{(n)}\right)+W_{2}^{2} Z_{1}^{(n)}} \dot{I}_{\mathrm{a} 3}
$$

where, the superscript $n$ is the harmonic number; $Z_{\mathrm{f}}^{(n)}$ is the filter impedance for the $n$-th harmonic. Therefore, the filter can eliminate the harmonic current, provided that the filter-side equivalent impedance is zero for the given harmonic. This is the precondition for the green operation of the grid.

\section{PARAMETER DESIGN}

Tabs. 1 and 2 present the basic technical parameters and iron core parameters of the proposed transformer, whose capacity is $30 \mathrm{kVA}$. The magnetization curve of the iron core material 27QG120 is shown in Fig. 3.

Table 1 Basic technical parameters

\begin{tabular}{|c|c|c|c|}
\hline Parameter & Grid side & Filter side & Valve side \\
\hline Rated capacity / kVA & 29.272 & 7.884 & 26.85 \\
\hline Rated voltage / V & 10000 & 380 & 380 \\
\hline Connection mode & $\mathrm{D}$ & $\mathrm{D}$ & and \\
\hline Line current / A & 1.69 & 11.98 & 40.79 \\
\hline Number of turns & 3236 & 123 & 71 \\
\hline
\end{tabular}

Table 2 Iron core parameters

\begin{tabular}{|c|c|}
\hline Iron core parameter & \\
\hline Diameter / mm & 85 \\
\hline Effective cross-section / $\mathrm{cm}^{2}$ & 88.56 \\
\hline Flux density / T & 1.61 \\
\hline Window height / mm & 510 \\
\hline Center distance / m & 320 \\
\hline Empty load loss / W & 227 \\
\hline Material & $27 \mathrm{QG} 120$ \\
\hline
\end{tabular}

After correcting the Rockwell coefficient, the widely used engineering magnetic circuit (EMC) method was introduced to compute the short-circuit impedance of the proposed transformer:

$X_{d(\%)}=\frac{49.6 f I N \sum D \rho}{E_{\mathrm{t}} h \times 10^{8}}$

where, $E_{\mathrm{t}}$ is the voltage per turn; $\sum D$ is the equivalent flux leakage area; $I N$ is the ampere turns; $\rho$ is the Rockwell coefficient. If the winding is concentric, then: 


$$
\left\{\begin{array}{c}
\rho=1+\frac{1}{\pi \mu}\left(\mathrm{e}^{-\pi \mu}-1\right) \\
\mu=\frac{h}{\lambda}
\end{array}\right.
$$

where, $h$ is the height of the leaking magnet group, i.e., the mean axial height of all windings in that group; $\lambda$ is the width of the missing magnet group, i.e., the sum of the spoke widths of all windings and leakage lanes in the leaking magnet group.

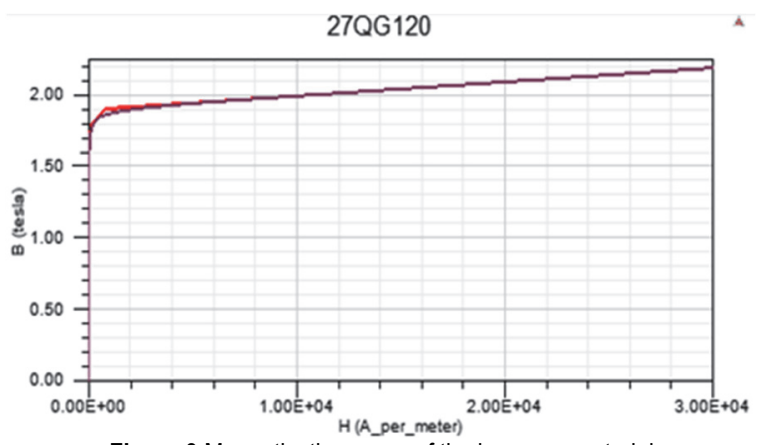

Figure 3 Magnetization curve of the iron core materia

Then, the impedance between windings (Tab. 3) was obtained from the winding scheme in Fig. 4.

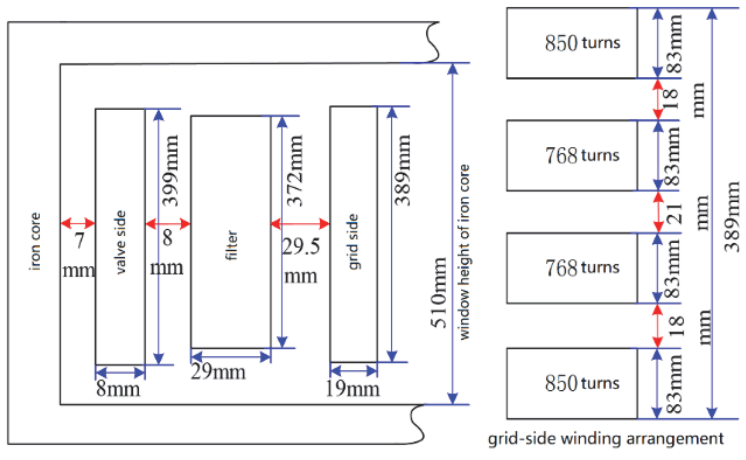

Figure 4 Winding scheme

Table 3 Impedance obtained by EMC method

\begin{tabular}{|c|c|c|}
\hline $\begin{array}{c}\text { Grid side - valve side } \\
/ \%\end{array}$ & $\begin{array}{c}\text { Grid side - filter side } \\
/ \%\end{array}$ & $\begin{array}{c}\text { Filter side - valve side } \\
/ \%\end{array}$ \\
\hline 4.994 & 3.706 & 1.105 \\
\hline
\end{tabular}

\section{SIMULATION}

\subsection{Finite-element Analysis}

This paper selects ANSYS Maxwell to develop the electromagnetic model of the proposed transformer. Fig. 5 summarizes the steps of the simulation and finite-element calculation.

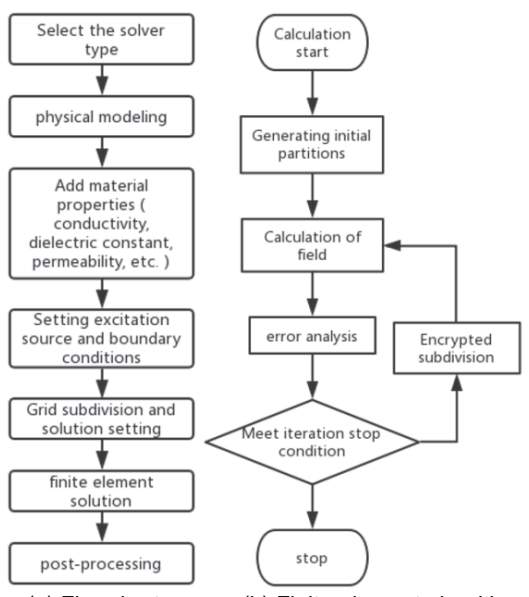

(a) Flowchart

(b) Finite-element algorithm

Figure 5 Steps of simulation and finite-element calculation

The first step is to select the type of solver, and establish a transient magnetic field under alternating excitation. The physical modeling of the proposed transformer was carried out, as shown in Fig. 6.

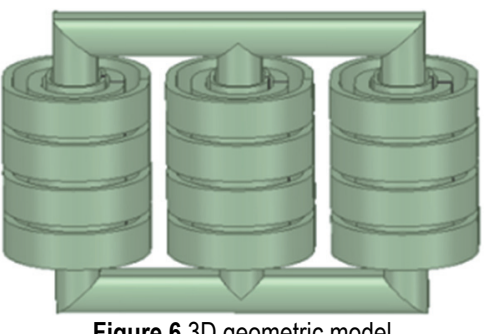

After adding materials, the current surface is cropped from the physical model for the addition of excitation. As shown in Fig. 7, the external circuit editor of ANSYS is adopted to apply an external circuit for field circuit coupling.

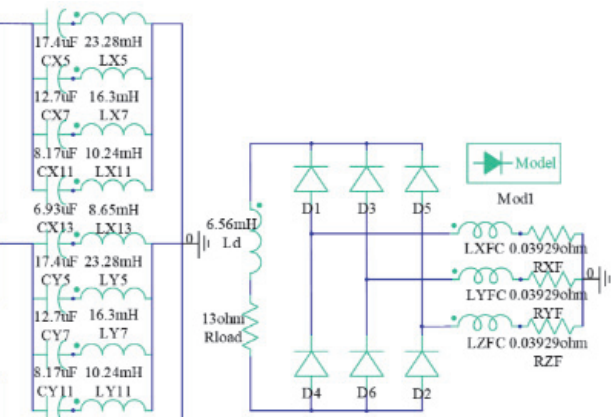

Three-phase winding connection of valve

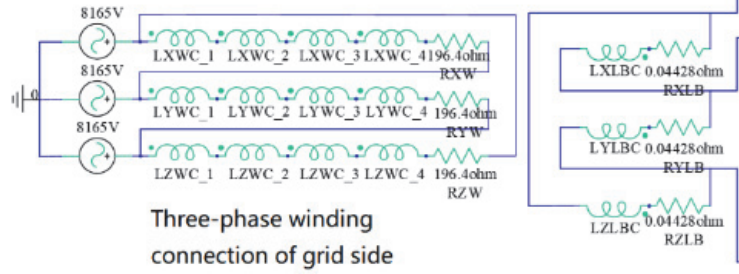

Three-phase winding connection of filter side
$6.93 \mathrm{nF}$
CY13
$8.65 \mathrm{mH}$
$\mathrm{LY} 13$

17.4 uा $23.28 \mathrm{mH}$

CZ5 2375

$\begin{array}{cc}2.7 \mathrm{HF} & 16.3 \mathrm{mH} \\ \mathrm{CZ7} & \mathrm{LZ7}\end{array}$

127.

C.17ur $10.24 \mathrm{mH}$

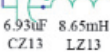

Figure 7 External circuit 
On the load side, a three-phase uncontrolled rectifier circuit was added to generate a $6 k \pm 1$ th harmonic. On the filter side, a single tuned filter was adopted to filter the 5 th, 7th, 11th and 13th harmonics.

After setting the boundary conditions, the field within the boundaries was meshed adaptively (Fig. 8).

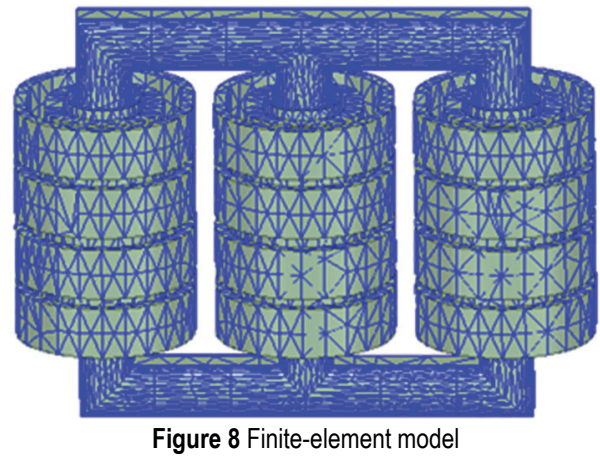

The core pillar and upper and lower yokes were meshed into 8068 grids; three windings of phase A were meshed into 4554 grids, the three windings of phase B were meshed into 4807 grids, and the three windings of phase $\mathrm{C}$ were meshed into 4574 units. The solution was set in ANSYS Maxwell. In addition, the step size and stop time were configured as $10 \mu \mathrm{s}$ and $0.5 \mathrm{~s}$, respectively. Through error analysis and iterative calculation, high-precision and reliable electromagnetic data were obtained.

\subsection{Winding Impedance Analysis}

The previous analysis reveals that the filtering performance of our DT must ensure that each winding meets the impedance condition. The design of our new transformer hinges on the calculation of model impedance by simulation software. The internal electromagnetic relationship of a transformer can be derived through the energy method, in a reliable and stable manner. Therefore, this paper selects the energy method to compute the impedances of transformer windings.

To measure the leakage reactance energy of transformer model on ANSYS Maxwell, the type of solver was set to the static magnetic field, using the natural boundary condition and adaptive meshing. In addition, an excitation was added to the given $3 \mathrm{D}$ model winding to measure the leakage reactance energy between two windings of each phase in turn. After the excitation was applied, it is necessary to add a DC current of equal size and opposite direction to the two windings to offset the current-induced main flux in the iron core. Then, it is possible to capture the cross-winding leakage flux, as well as the leakage magnetic field energy $W_{\mathrm{mf}}$. Fig. 9 shows the application of excitation for measuring short-circuit impedance.
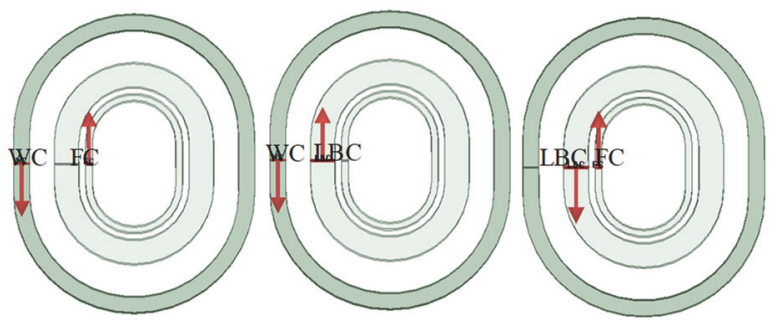

Figure 9 Application of excitation for measuring short-circuit impedance

Let $L_{\mathrm{d}}$ be the cross-winding short-circuit leakage; $I_{\mathrm{d}}$ be the DC current on the winding. The value of $W_{\mathrm{mf}}$ on a winding can be calculated by:

$W_{\mathrm{mf}}=\frac{1}{2} L_{\mathrm{d}} I_{\mathrm{d}}^{2}$

Then, the short-circuit reactance $X_{\mathrm{d}}$ can be obtained by

$X_{\mathrm{d}}=2 \pi f \cdot L_{\mathrm{d}}=2 \pi f \cdot \frac{2 W_{\mathrm{mf}}}{I_{\mathrm{d}}^{2}}$

After normalization:

$X_{\mathrm{d}^{*}}=\frac{U_{\mathrm{m}}}{U_{\mathrm{b}}}=\frac{X_{\mathrm{d}} \cdot S}{3 \cdot U_{\mathrm{b}}^{2}}$

Next, the cross-winding $W_{\mathrm{mf}}$ was obtained by the energy method, while the cross-winding short-circuit impedance was computed by Eqs. (10) to (12), and compared with the results obtained by the EMC method (Tab. 4). The comparison shows that the two methods produced similar impedances, with an error smaller than $5 \%$. Therefore, our DT meets the impedance requirement on each winding.

Table 4 Results of energy method vs. results of EMC method

\begin{tabular}{|c|c|c|c|}
\hline Winding & Simulated $W_{\mathrm{mf}} / \mathrm{J}$ & Impedance (energy method) $/ \%$ & Impedance $($ EMC) $/ \%$ \\
\hline Grid side - valve side & 0.83653 & 5.156 & 4.994 \\
\hline Grid side - filter side & 0.62395 & 3.82 & 3.706 \\
\hline Filter side - valve side & 0.000244 & 1.062 & 1.105 \\
\hline
\end{tabular}

\subsection{Simulation Results}

Our DT was verified through ANSYS simulation. The peak phase voltage on the grid side was set to $8165 \mathrm{~V}$. A three-phase uncontrolled rectifier was deployed on the valve side to generate a $6 k \pm 1$ the harmonic. The load resistance was set to $13 \Omega$, and the smoothing reactor to $6.56 \mathrm{mH}$.

Fig. 10 shows the grid- and valve-side flux densities of traditional dual winding transformer and our DT. The traditional and our DTs had almost the same grid-side flux density, whose wave form was severely distorted. After filtering, the grid-side flux density of our DT approximated the sine wave, indicating that our DT can filter out the harmonic flux.

Fig. 11 is the simulation result of one-phase current of the fully tuned branch at the filter side of the IF DT. The turns ratio of filter side winding to valve side winding is set to $1: 1$, and the harmonics generated by the valve side uncontrolled rectifier equipment are filtered through the filter side. 

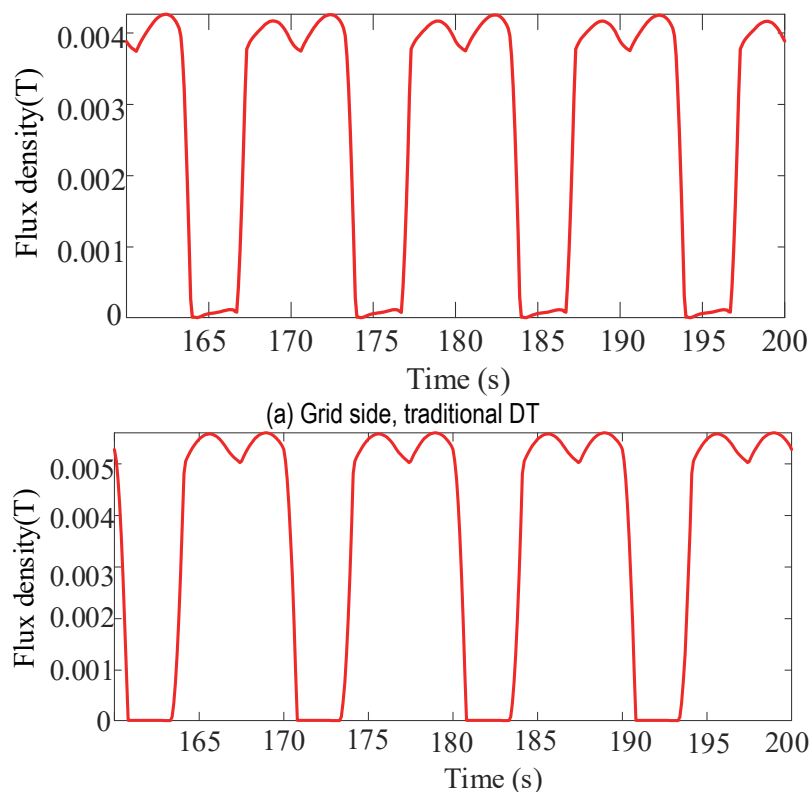

(b)Valve side, traditional DT
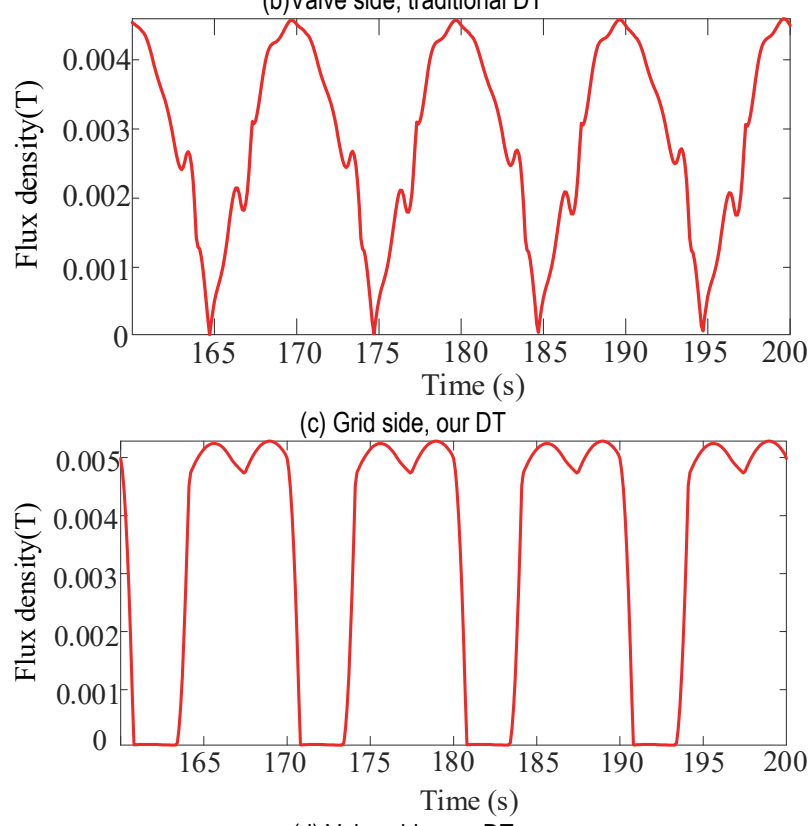

(d) Valve side, our DT

Figure 10 Grid- and valve-side flux densities of traditional DT and our DT

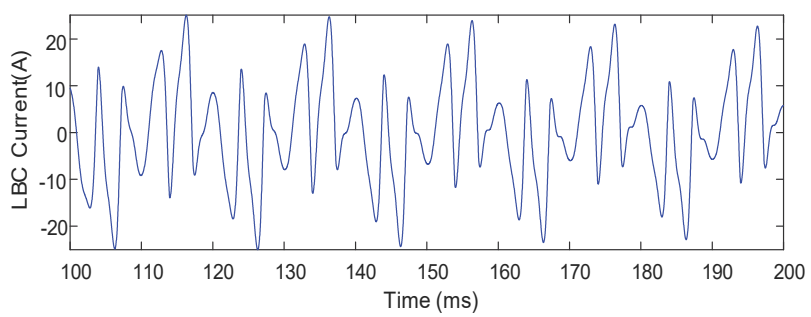

Figure 11 Current of the fully tuned branch at the filter side of the IF DT

Fig. 12 compares the grid-side currents of traditional dual winding transformer and our DT. The two transformers were consistent in the waveform of grid-side current. Both witnessed severe harmonic pollution in the grid. Our DT filtered out most of the valve-side harmonic current, such that the grid-side current basically took the shape of the sine wave. Hence, our DT design is correct.

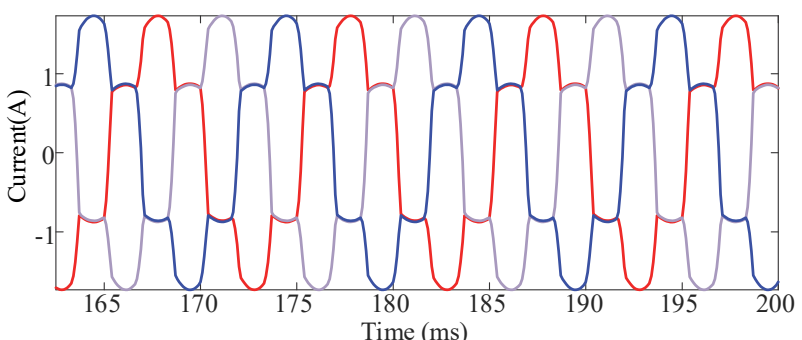

(a) Traditional DT

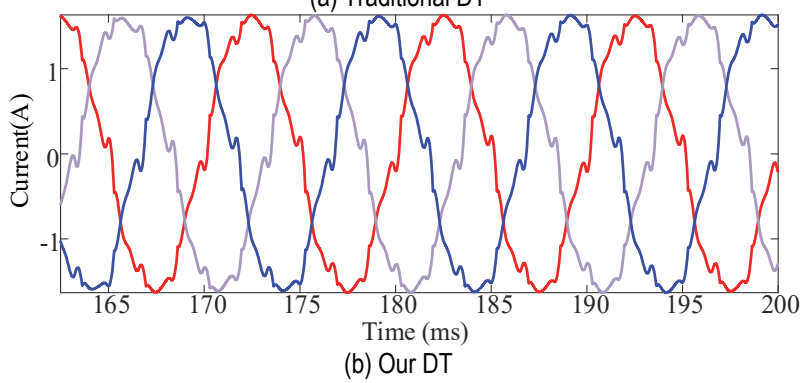

Figure 12 Grid-side currents of traditional DT and our DT

\section{EXPERIMENTAL VALIDATION \\ 5.1 Scenarios and System Parameters}

Our DT design was further verified through experiment. The wiring diagram and test platform are displayed in Figs. 13 and 14, respectively. Four single tuned filters were selected for the experiment, that is, the cumulative capacity amounted to $6.98 \mathrm{kVA}$. The generations of harmonic and load resistance were implemented in the same manner as in the previous simulation. Then, the cross-winding impedance of our DT was measured through a short-circuit test (Tab. 5).
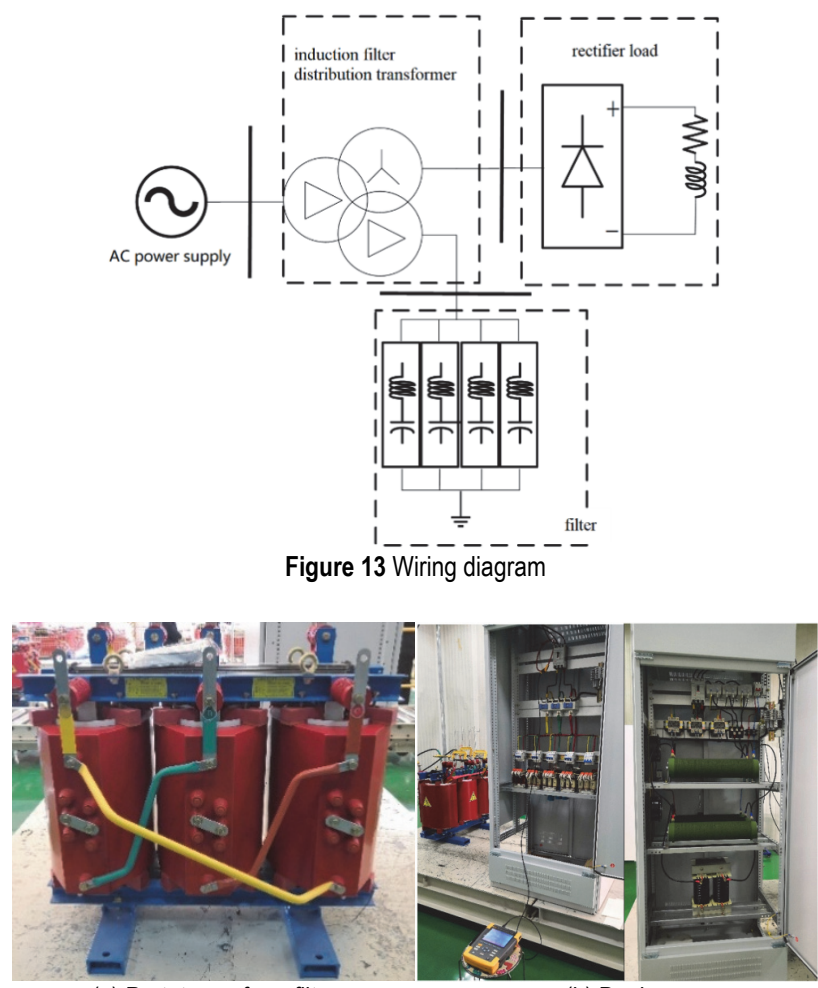

(a) Prototype of our filter

(b) Device

Figure 14 Experimental platform

Table 5 Measured impedances

\begin{tabular}{|c|c|c|}
\hline $\begin{array}{c}\text { Gridside - valve side / } \\
\%\end{array}$ & $\begin{array}{c}\text { Grid side - filter side } \\
/ \%\end{array}$ & $\begin{array}{c}\text { Filter side - valve side } \\
/ \%\end{array}$ \\
\hline 5.29 & 4.12 & 1.26 \\
\hline
\end{tabular}


The impedances measured through our experiment were within $5 \%$ from the results obtained through the energy method and the EMC method. This is in line with the design expectations.

When the grid-side voltage was $10000 \mathrm{~V}$, the no-load voltage on that side was measured as $382 \mathrm{~V}$, which meets the voltage requirements of transformer design.

\subsection{Filtering Effect}

Fig. 15 compares the grid-side currents of the traditional and our DTs. Fig. 16 displays the spectra of the collected current waveforms. Comparing Figs. 15 and 16, it could be inferred that, for the grid-side current, the rate of harmonic distortion was as high as $24.63 \%$. Our DT lowered that rate to $3.94 \%$, suggesting that our design can effectively eliminate harmonics.

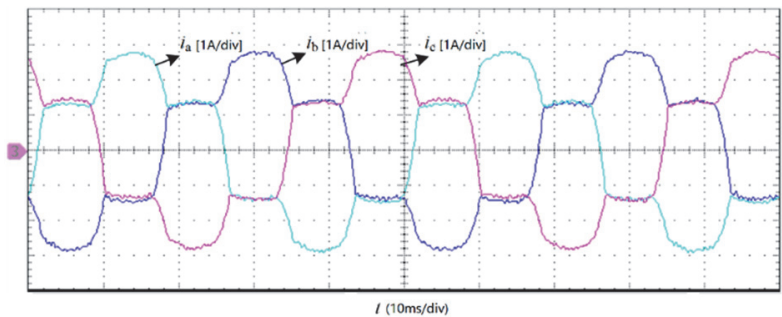

(a) Traditional DT

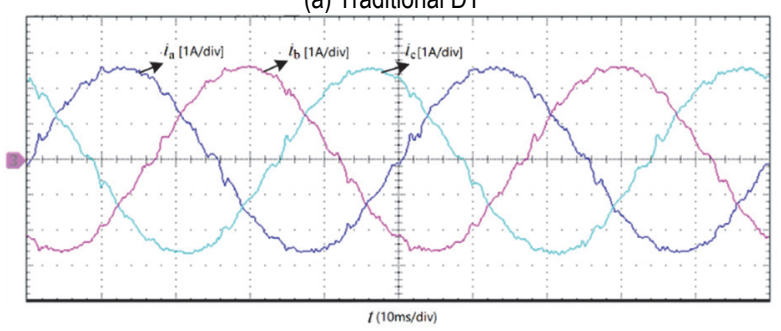

(b) Our DT

Figure 15 Grid-side currents of the traditional and our DTs

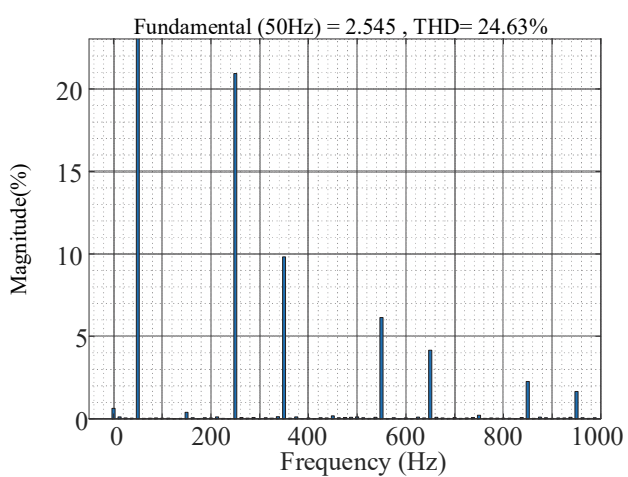

(a) Traditional DT

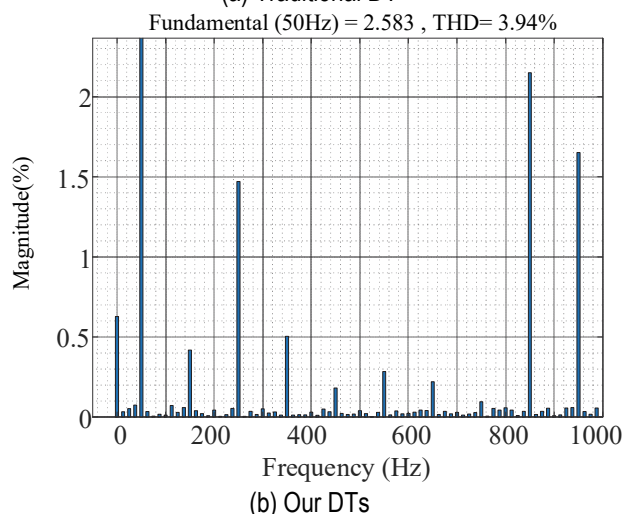

Figure 16 Spectra of the collected current waveforms

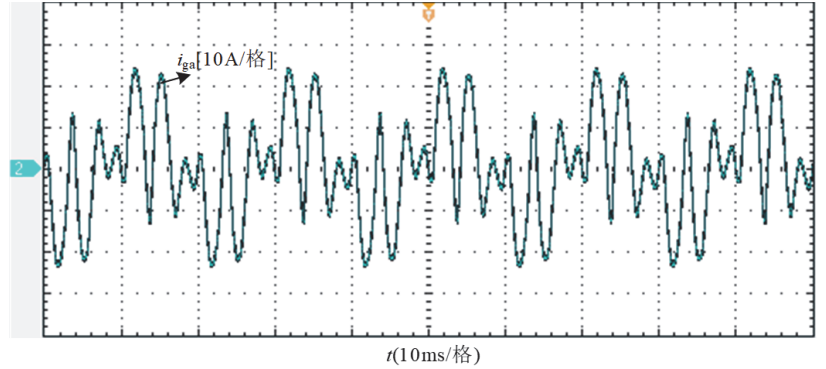

Figure 17 Current of the fully tuned branch at the filter side of the IF DT

Fig. 17 proves that the fully tuned branch on the filter side of the IF DT induces the harmonic component generated on the valve side, which further shows that the IF DT effectively eliminates the harmonic.

\section{CONCLUSIONS}

To popularize the application of IF technology in LV distribution network, this paper puts forward a novel IF DT for LV distribution networks. The designed transformer was firstly validated on ANSYS Maxwell. The simulation results indicate that our DT can effectively filter harmonics. Then, the voltage parameters of the transformer and the cross-winding impedances were obtained under the no-load and short-circuit states. The impedances measured through our experiment were within 5\% from the results obtained through the energy method and the EMC method. This is in line with the design expectations. Through the filter experiment, it is proved that the designed IF transformer maintains the structure of the traditional LV DT, can deal with unbalanced load, and has excellent harmonic suppression ability. The comprehensive innovation experiment not only verifies the correctness of our design, but also effectively arouses the students' enthusiasm for transformer innovation.

\section{Acknowledgements}

This paper is supported by Natural Science Research Project of Universities, Department of Education, Jiangsu Province (Grant No. 18KJB470024), Funding Project for Professional Leaders of Higher Vocational Colleges in Jiangsu Province (Grant No. 2020GRFX031), and National Key Research and Development Program for Central Universities (Grant No. 2016YFC0600804).

\section{REFERENCES}

[1] Bishop, M. T., Baranowski, J. F., Heath, D., \& Benna, S. J. (1996). Evaluating harmonic-induced transformer heating. IEEE transactions on power delivery, 11(1), 305-311. https//doi.org/10.1109/61.484029

[2] Said, D. M., Nor, K. M., \& Majid, M. S. (2010). Analysis of distribution transformer losses and life expectancy using measured harmonic data. Proceedings of 14th International Conference on Harmonics and Quality of Power-ICHQP 2010, 1-6. https//doi.org/10.1109/ichqp.2010.5625404

[3] Zhou, G., Li, Y., Chen, Y., Luo, L., \& Zhou, Y. (2015). Principle research on suppressing harmonic instability of HVdc transmission by using an inductive filtering method. 2015 5th International Conference on Electric Utility Deregulation and Restructuring and Power Technologies (DRPT), 1710-1714. 
https//doi.org/10.1109/DRPT.2015.7432509

[4] Xu, J., Gu, X., Liang, C., Bai, Z., \& Kubis, A. (2017). Harmonic suppression analysis of a harmonic filtering distribution transformer with integrated inductors based on field-circuit coupling simulation. IET Generation, Transmission \& Distribution, 12(3), 615-623. https//doi.org/10.1049/iet-gtd.2017.1153

[5] Li, Y., Yao, F., Cao, Y., Liu, W., Liu, F., \& Hu, S. (2016). An inductively filtered multiwinding rectifier transformer and its application in industrial DC power supply system. IEEE Transactions on Industrial Electronics, 63(7), 39873997. https//doi.org/10.1109/TIE.2016.2532282

[6] Li, Y., Saha, T. K., Krause, O., Cao, Y., \& Rehtanz, C. (2013). An inductively active filtering method for powerquality improvement of distribution networks with nonlinear loads. IEEE transactions on power delivery, 28(4), 24652473. https//doi.org/10.1109/TPWRD.2013.2273941

[7] Shao, P., Luo, L., Li, Y., Xu, J., He, D., \& Liu, F. (2008). Application prospect of a new transformer inductive filtering technology. 2008 Third International Conference on Electric Utility Deregulation and Restructuring and Power Technologies, 1847-1852. https//doi.org/10.1109/DRPT.2008.4523707

[8] Liu, Q. \& Li, Y. (2020). An inductive filtering-based parallel operating transformer with shared filter for power quality improvement of wind farm. IEEE Transactions on Power Electronics, 35(9), 9281-9290. https//doi.org/10.1109/TPEL.2020.2973702

[9] Li, Y., Luo, L., Rehtanz, C., Ruberg, S., Yang, D., \& Xu, J. (2011). An industrial DC power supply system based on an inductive filtering method. IEEE Transactions on Industrial Electronics, 59(2), 714-722. https//doi.org/10.1109/TIE.2011.2161245

[10] Yang, D., Li, Y., Rehtanz, C., Luo, L., \& Xu, J. (2010). Study on harmonic losses of inductive filtering converter transformer (IFCT) in HVDC system. 2010 Asia-Pacific Power and Energy Engineering Conference, 1-4. https//doi.org/10.1109/APPEEC.2010.5449294

[11] Liu, Q., Li, Y., Liu, F., Hu, S., Xie, B., Luo, L., \& Cao, Y. (2016). A controllably inductive power filtering method for large-power industrial rectifier system. 2016 IEEE 16th International Conference on Environment and Electrical Engineering (EEEIC), 1-5. https//doi.org/10.1109/EEEIC.2016.7555468

[12] Peng, Y., Li, Y., Lee, K. Y., Liu, F., Yang, F., \& Hu, B. (2017). A wind power integrated system based on a controllably inductive filtering and compensation method. 2017 IEEE Power \& Energy Society General Meeting, 1-5. https//doi.org/10.1109/PESGM.2017.8273899

[13] Xu, Z., Peng, Y., Li, Y., Wen, M., Luo, L., Cai, Y., \& Cao, Y. (2015). Improvement of power quality and dynamic voltage of wind farms using an inductive filtering method. 2015 IEEE 15th International Conference on Environment and Electrical Engineering (EEEIC), 1611-1615. https//doi.org/10.1109/EEEIC.2015.7165412

[14] Li, Y., Luo, L., Nakamura, K., Rehtanz, C., Zhang, J., Xu, J., $\&$ Liu, F. (2008). Transient response characteristics of new HVDC transmission system based on new converter transformer. 3rd International Conference on Deregulation and Restructuring and Power Technologies, DRPT 2008, 1873-1877. https://doi.org/10.1109/DRPT.2008.4523712

[15] Li, Y., Luo, L., Rehtanz, C., Nakamura, K., Xu, J., \& Liu, F. (2009). Study on characteristic parameters of a new converter transformer for HVDC systems. IEEE Transactions on Power Delivery, 24(4), 2125-2131. https://doi.org/10.1109/TPWRD.2009.2021033

[16] Li, Y., Luo, L., Rehtanz, C., Rüberg, S., \& Liu, F. (2012). Realization of reactive power compensation near the LCCHVDC converter bridges by means of an inductive filtering method. IEEE Transactions on Power Electronics, 27(9),
3908-3923. https://doi.org/10.1109/TPEL.2012.2189587

[17] Li, Y., Luo, L., Rehtanz, C., Yang, D., Rüberg, S., \& Liu, F. (2012). Harmonic transfer characteristics of a new HVDC system based on an inductive filtering method. IEEE Transactions on Power Electronics, 27(5), 2273-2283. https://doi.org/10.1109/TPEL.2011.2171998

[18] Peng, Y., Li, Y., Liu, F., Luo, L., \& Cao, Y. (2016). A new shipboard power supply system based on a rectifier transformer with integrated filtering reactor. 2016 IEEE Transportation Electrification Conference and Expo, AsiaPacific, ITEC Asia-Pacific 2016, 402-406. https://doi.org/10.1109/ITEC-AP.2016.7512986

[19] Corasaniti, V. F., Barbieri, M. B., Arnera, P. L., \& Valla, M. I. (2009). Hybrid power filter to enhance power quality in a medium-voltage distribution network. IEEE Transactions on Industrial Electronics, 56(8), 2885-2893. https//doi.org/10.1109/TIE.2009.2014369

[20] Mahmood, F., Vanfretti, L., Pignati, M., Hooshyar, H., Sossan, F., \& Paolone, M. (2018). Experimental validation of a steady state model synthesis method for a three-phase unbalanced active distribution network feeder. IEEE Access, 6, 4042-4053. https//doi.org/10.1109/ACCESS.2018.2792320

[21] Luo, L., Li, Y., Xu, J., Li, J., Hu, B., \& Liu, F. (2008). A new converter transformer and a corresponding inductive filtering method for HVDC transmission system. IEEE Transactions on Power Delivery, 23(3), 1426-1431. https//doi.org/10.1109/TPWRD.2008.919160

[22] Zhang, X., Li, C., Li, D., \& Jiang, S. (2021). Study on Operation Parameter Characteristics of Induction Filter Distribution Transformer in Low-voltage Distribution Network (April 2021). IEEE Access. https://doi.org/10.1109/ACCESS.2021.3083750

[23] Yong, J., Chen, L., \& Chen, S. (2010). Modeling of home appliances for power distribution system harmonic analysis. IEEE Transactions on Power Delivery, 25(4), 3147-3155. https://doi.org/10.1109/TPWRD.2010.2051960.

\section{Contact information:}

Delu LI

(Corresponding author)

School of Electrical and Power Engineering,

China University of Mining and Technology,

Xuzhou 221116, China

Jiangsu Vocational Institute of Architectural Technology,

Xuzhou 221116, China

E-mail: leedelu@jsjzi.edu.cn

\section{Xianming DENG}

School of Electrical and Power Engineering,

China University of Mining and Technology,

Xuzhou 221116, China

E-mail: xmdengcumt@126.com

\section{Changyi LI}

School of Electrical and Power Engineering,

China University of Mining and Technology,

Xuzhou 221116, China

E-mail: 756046422@qq.com

\section{Xiao ZHANG}

School of Electrical and Power Engineering,

China University of Mining and Technology,

Xuzhou 221116, China

E-mail: 2093@cumt.edu.cn

\section{En FANG}

School of Electrical and Control Engineering,

Xuzhou University of Technology,

Xuzhou 221116, China

E-mail:18352268788@163.com 